\title{
ICT Leap-frogging Enabled by Cloud Computing for Emerging Economies: A Case Study on Streamlining India's Grain Supply Chains
}

\author{
Jacob Tsao, Shailaja Venkatsubramanyan, Shrikant Parikh and Prasenjit Sarkar
}

\begin{abstract}
Cloud computing enables use of computing without user-side hardware, software and associated financial and knowledge requirements, except for the needs of a simple "webterminal" and access to the internet. Emerging economies can fully capitalize on this to start a "revolution" and leap-frog developed nations by skipping completely the several major computing architectures gone through in developed nations. An analogy is the leap-frogging, that has taken place with wireless telephony. We briefly introduce our research into streamlining India's grain supply chains and then discuss in detail on how cloud computing can play a pivotal role. Although the focus is on the portion of the supply chains between wholesalers and consumers, we also discuss how cloud computing can streamline the entire supply chains and how it offers leap-frogging opportunities for the entire society. The proposed use of webterminals for accessing the cloud for all computing needs is new, and we point out several high-impact research subjects.
\end{abstract}

Index Terms - Cloud Computing, web-terminal, wireless access, Leap-frogging, Grain Supply Chains, Logistics, Hubbing, Branding, Developing Nations, India

\section{INTRODUCTION}

$\mathrm{C}$ loud computing has been motivated in developed nations to support the new paradigms of software as a service, hardware as a service, platform as a service, etc. [1,2]. However, it may be more beneficial to emerging economies like India. This is because countries like India can leap-frog developed nations in use of computing by directly migrating to the paradigm of cloud computing and skipping the less efficient intermediate computing architectures. Note that this direct migration can virtually free users from the need to own computing hardware (stand-alone or networked personal

Manuscript received on March 01, 2011. Accepted July 16, 2011.

Jacob Tsao is Professor of Industrial and Systems Engineering at San Jose State University. He taught and conducted research at S.P. Jain Institute of Management and Research of Mumbai, India for four months during his sabbatical leave in the 2009 - 2010 academic year. (jacob.tsao@ sjsu.edu)

Shailaja Venkatsubramanyan is Associate Professor of Management Information Systems at San Jose State University. (shailaja.venkatsubramanyan@sjsu.edu)

Shrikant Parikh is with S.P. Jain Institute of Management and Research. (drsparikh@gmail.com)

Prasenjit Sarkar is with IBM Almaden Research Center, San Jose. (psarkar@almaden.ibm.com) computers) and client-side software. All such intermediate architectures also require the expertise and/or labor about their installation, operation, trouble-shooting, maintenance, upgrade, etc. These cost and knowledge requirements have been a barrier for the general population in an emerging economy to benefit from computing and the Internet. Cloud computing possesses the potential for removal of this and other barriers. Although cloud-computing researchers have expressed the opinion that emerging economies can benefit from cloud computing, they tended to seek general application areas for cloud computing, e.g., government services, or suggested further development of technologies, e.g., voice-enabled web portal, that may facilitate the adoption of cloud computing by emerging economies [3]. We have had an entirely different motivation - to streamline and improve India's grain supply chain and, in the process, discovered that cloud computing is a promising technology for solving a key part of the problem [4].

A major problem in India's grain supply chains is spoilage. Spoilage rates in these supply chains have been consistently estimated to be between $25 \%$ and $30 \%$, with their developednation counterparts being approximately $3 \%[3,4]$. The rates of price "mark-up," i.e., service charges over crop costs, have been estimated to be over $240 \%$, with their counterparts in developed nations being between $50 \%$ and $100 \%[3,4]$. Moreover, food prices have been steadily growing. This points to not only the importance but also the urgency of streamlining grain supply chains of India. Improving India's grain supply chains has the potentials of better food quality and lower retail prices for the consumers and higher profits for the farmers. In addition, improving profit margins for the vast number of subsistence grain farmers may reduce population migration from rural areas to large cities; such migration has been attributed as a reason for the existence or expansion of some urban slums. This research was motivated to develop service, information technology and logistics concepts that can help streamline India's grain supply chains.

We focus on the portion of the supply chains between the wholesalers and the consumers, and this portion accounts for a whopping $210 \%$ of the $240 \%$ overall price mark-up $[3,4]$. 
A layer of intermediaries (i.e., middlemen) exists between the wholesalers and the retailers, and they serve three major functions: checking prices offered by a large number of small wholesalers, checking quality of grains carried by the wholesalers, and paying for the merchandizes at the time of shipping on behalf of the retailers. Cloud computing has the potential of automating the functions of price checking and advance payment. It can also allow retailers to access directly information about many existing "private, unwritten brands," which are currently understood only between the wholesalers and the middlemen, and hence has the potential for automating the function of quality checking as well. Together with other improvements in supply-chain operations, particularly the concept of "consumer visible" branding, this layer of intermediaries can be drastically reduced in importance or even completely eliminated, hence significantly reducing the supply-chain costs. In addition to cloud computing and branding, the solution we proposed in [4] to help reduce the cost of the supply chains between wholesalers and consumers has another pillar - distributed hubbing for drastically reducing the distribution cost.

Unlike how cloud computing is used in developed nations $[1,2]$, the two primary benefits of cloud computing for streamlining India's grain supply chains and improving the operations of many other systems in emerging economies are about the access to computing, not about the computing that can be performed in the cloud. A feature of cloud computing is the requirement of a "thin client," as originally promoted in the 1990's by Sun Microsystems. This feature is actually an unsung hero from the perspective of emerging economies. This is because the minimum requirement for access to the cloud is a "web-terminal." Such web-terminals serve only the purpose of accessing the internet through a browser and require little memory and computing power. They can be very inexpensive, unlike some of the sophisticated "Smart Phones" serving as popular high-end cell phones and mobile internet-access devices in developed nations. In addition, there is no need for owning software, whose purchase and upgrading could be expensive for the majority of the population of an emerging economy; the charge of on-demand software may be much more affordable. This points to the first primary benefit of cloud computing - low cost. The second primary benefit is low knowledge requirement. With the simplicity of such web-terminals and with the computing hardware and software applications residing in the cloud, the user is no longer required to install, maintain, recover, or upgrade either hardware or software. This architecture can be referred to as 'pure cloud computing' or simply 'pure cloud'.

Cost and knowledge requirements are two major barriers for the grain retailers to access and use computing, and such barriers led to their continued complete reliance on the intermediaries and, consequently, to continued high service charges in this portion of the supply chains. (Lack of public accessible price information also led to continued incidences of price-gouging by some merchants in this portion of the supply chains). The proposed "pure cloud computing" can drastically lower the two requirements and provide unprecedented opportunities for the retailers to benefit from computing and the Internet. This type of operational concepts provides a leap-frogging opportunity for the entire Indian society in general to more quickly than otherwise benefit from the power of computing by moving directly toward (public and/or private) cloud computing, bypassing the conventional steps of stand-alone computing, client-server architecture, networked computing, software as a service, hardware as a service, etc. As will be pointed later, although such leapfrogging is quite feasible for urban and suburban area, where access to the internet is already prevalent and hence is not a big issue, significant challenges exist for such leap-frogging to take place in rural or remote areas due to low accessibility to the Internet. However, we argue that similar leap-frogging directly to cloud computing for rural and remote areas should still be the goal because it should be much less costly than going through the stage of personal computing and the other traditional computing architectures. An analogy to this ICT leap-frogging is the leap-frogging having been taking place with wireless telephony. The market penetration for cell phones has reached $50 \%$ in just 10 years while its counterpart for land-line telephony is still $18 \%$ despite of 50 years of deployment. In fact, much of the benefit enabled by access to computing via the internet can be reaped, at least during initial deployment of the proposed operational concept, with the almost ubiquitous cell-phone technology and with some basic services like Google SMS Applications, particularly Google SMS Search [5,6].

The rest of this paper is organized as follows. Section II describes the problem of streamlining India's grain supply chains. Section III proposes a new operational concept as a solution for the problem and addresses its feasibility and benefits. It focuses on two pillars of the operational concept "consumer visible" branding and distributed hubbing for the portion of supply chains between the wholesalers and the consumers, and the discussion is brief. Section IV focuses on the other pillar of cloud computing and addresses its feasibility and its leap-frogging benefits. Section V discusses briefly how cloud computing and ICT can significantly improve the operations of the rest of India's grain supply chains. Section VI discusses the success and hindrance factors for the proposed improvement via cloud computing. Section VII discusses the promising leap-frogging role cloud computing can play in drastically lowering barriers to use of computing for the entire society of an emerging economy. Concluding remarks are given in Section VIII.

\section{INDIA'S GRAIN SUPPLY CHAINS}

The produce supply chains of India have long been rather organized, with heavy well-intentioned government participation through provision of physical trading facilities and legal regulations. For example, each city has a Agriculture Produce Marketing Committee (APMC) that 
owns and operates one wholesale market for each of several major types of produce, e.g., grains, pulses, spices and perishable produces, at which wholesalers store, display to brokers (between the wholesalers and the retailers), trade with the brokers and transship the produce. Such markets of a city were originally intended for direct trading between farmers and retailers. As scales of agricultural activities grew larger and more specialized, such direct trading became difficult, if not impossible. For example, grains are grown mostly in Punjab and other northern states of India and transported to meet the consumer needs of all parts of India. Crops are consolidated by brokers (or directly transported by farmers) for sale to grain traders at the local APMC, called Mundi at the farmer or supplier side of supply chains. Typically, another layer of brokerage lies between these traders and milling companies, which sell their products to wholesalers through yet another layer of brokerage. Between the wholesalers and the consumers are the retailers and the brokers between the wholesalers and the retailers. These supply chains are illustrated in Figure 1.

We found few articles addressing this severe problem in international journals or conferences. After summarizing India's current grain supply chains and how the spoilage and mark-up rates accumulated through the chain, Sachan et al. [7] and Sachin et al. [8] proposed, with a System Dynamics approach, cost models for three supply-chain-integration alternatives for grains (namely cooperative supply chain model, collaborative supply chain model and contract farming). Few Indian journal or conference articles about grain supply chains were found, e.g., [9,10]. Several Indian agencies and news organizations have published research reports on these and general supply chains, e.g., [11,12,13].

\section{A. Major Causes of the Problem Pointed Out in the} Existing Literature

Major root causes of the problems of high spoilage and price mark-up pointed out in the literature include [12]:

- "Lack of adequate storage and transport infrastructure at the village level and right through the supply chain, which results in loss of output to rodents, pilferage, spoilage, etc.

- Presence of a large number of intermediaries, which results in a high mark-up to the end consumer".

Farmers

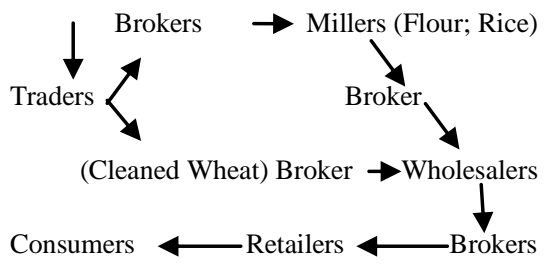

Fig. 1. India's grain supply chains
Indian government plays a big role in food supply chains. ICRA [12] states, "A plethora of laws, often overlapping in coverage, regulates the Indian food industry".

\section{B. Implemented Partial Solutions and Current Improvement Efforts}

In response to this severe problem, efforts have been made to alleviate it. A successful effort is eChoupal.com initiated and operated by ITC Ltd. of India [14]. eChoupal.com, accessed from personal computers through phone lines or satellites by trained farmers as conduits of information for farmers residing within a distance of approximately 5 kilometers, allows farmers to know the current commodity prices so that they can time the sale of their crops accordingly. ITC also purchases crops from farmers but with advanced equipment, e.g., automatic weight scale, quality-test lab, etc., and with a system of modern procurement practices, e.g., establishing quality standards based on numerical measures, quality-sensitive pricing, online price negotiation, etc. It also educates farmers on modern agricultural practices for better yield and better quality. It is important to note that much of this modernization would not have been possible without the IT infrastructure of eChoupal. Also, coverage of eChoupal expands as the IT infrastructure does. While eChoupal focuses on the farmer side of the supply chains, our focus is on the consumer side.

A small number of grocery supermarket chains have been founded in recent years and a small portion of the grain supply chains of India have been modernized. Reliance Fresh is one of them. However, accordingly to our sources, it continues to rely on wholesalers for its supply but D-Mart , another small supermarket chain, directly sources its grains from the millers or even the farmers, hence shortening the supply chains.

\section{Our Focus and Improvement Opportunities}

We focused on Mumbai, India for a case study and conducted a number of site visits to interview wholesalers, sales brokers for wholesalers (i.e., purchase brokers for the retailers), retailers, managers of APMC (which is the nationwide government agency regulating the grain and produce supply chains ), and even purchase brokers for the wholesalers (i.e., sales brokers for the millers), among other key participants in the supply chains.

The large number of brokers involved in India's grain supply chains has been blamed for the high mark-up and spoilage rates. Although some brokers have engaged in price gouging, brokers intermediating between different pairs of other participants of the supply chains do serve multiple functions in the current supply chains. Take the retailers' perspective for example. The purchase brokers for a retailer (i.e., the sales brokers for a wholesaler) are actually needed in the current system to (i) investigate the highly variable quality levels offered by a wholesaler for one grain variety through time, not to mention the variability associated with a large 
number of wholesalers, (ii) search or negotiate for the best prices among many different wholesalers offering desired quality, and (iii) make advance payments to the wholesalers before collecting payments from the purchasing retailers (and bear the risk of non-payment by some retailers). The Mumbai APMC consists of three separate markets dedicated to three produce types: grains/pulses, spices and fresh produces. 600 wholesalers, 1500 brokers and 3500 trucks work at the grains/pulses market and serve all 15 million residents of Mumbai, India. Each of these 600 wholesalers occupies only a small, rectangular storage area of an approximately 1,700 square feet. The neighboring wholesale spaces share two walls; samples of up to over 50 varieties of grains are

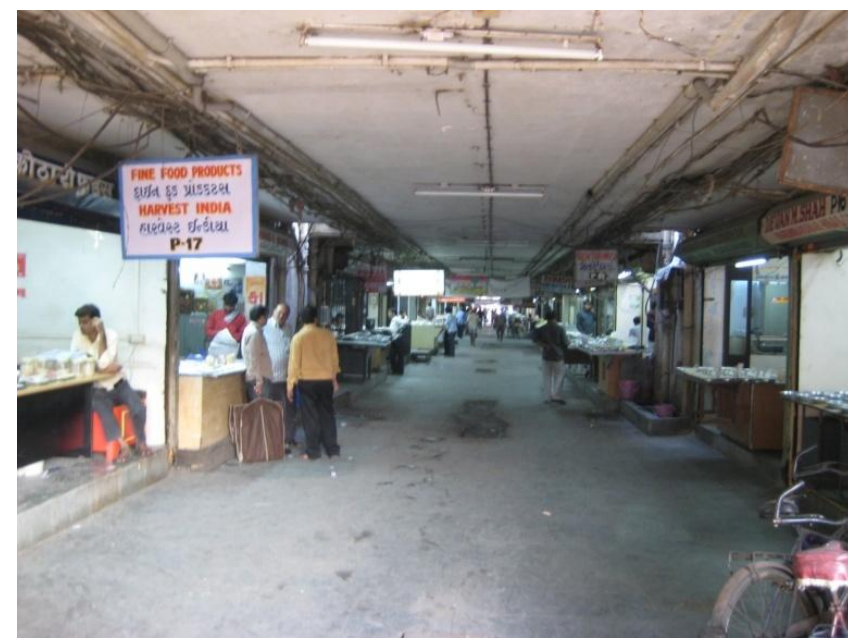

Fig. 2. 30 wholesale spaces in one of 20 identical buildings

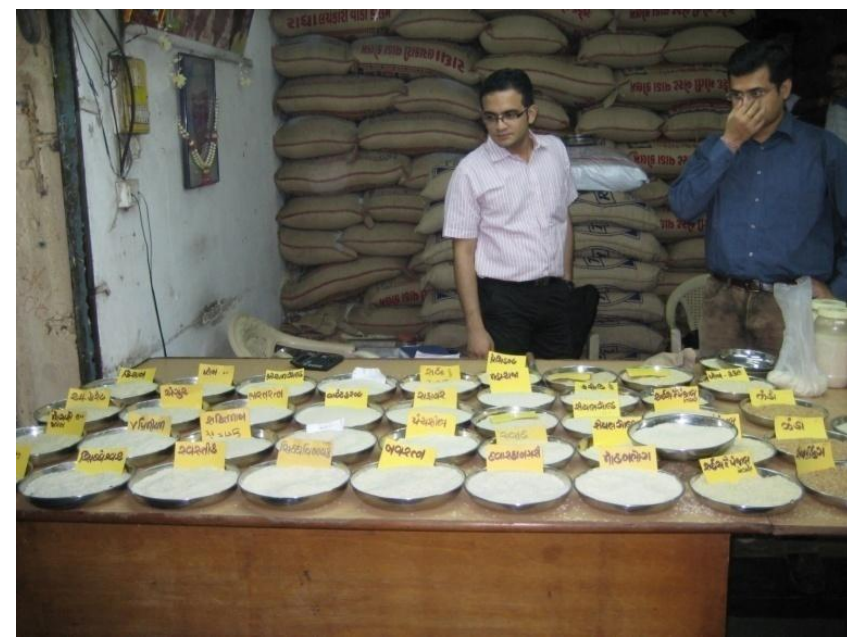

Fig. 3. A typical display of private brands at a wholesaler

displayed on tables placed at the narrow storefront, which is approximately 20 -feet long and opposite of the loading dock. The 600 stores occupy 20 virtually identical buildings.

A typical storefront display of sample merchandise consists of small trays labeled with "private brands." Note that these "brands" are currently understood only between wholesalers and the middlemen (i.e., purchase brokers of retailers). Although each wholesale store is quite small, computer use is an integral part of the operation. In fact, Mumbai APMC develops software for the wholesalers. Retail operations tend to be small as well; a typical neighborhood retail store specializing in staple grains and pulses may have a storefront of 8 to 12 feet. It is safe to assume that operating a typical retailer does not require much knowledge. These motivated our search for a low-cost and low-knowledge-requirement ICT solution to help streamline the supply chains.

We note that according to the current regulations, APMC markets on the consumer side of the grain supply chains are the only locations, with few exceptions or "loopholes" where wholesale activities can be conducted and from which all the grains to be consumed by the city residents are transshipped. As cities and their populations grow larger, APMC markets outgrow their original confines, and some such markets have been relocated to city outskirts or even neighboring cities. For example, the APMC markets of Mumbai, including the grains/pulses market, spice market and fresh-produce markets, moved out of Mumbai altogether and into the neighboring city of Navi Mumbai. Serving the grain needs of a large city through a single out-of-the-city grain hub induces drastically

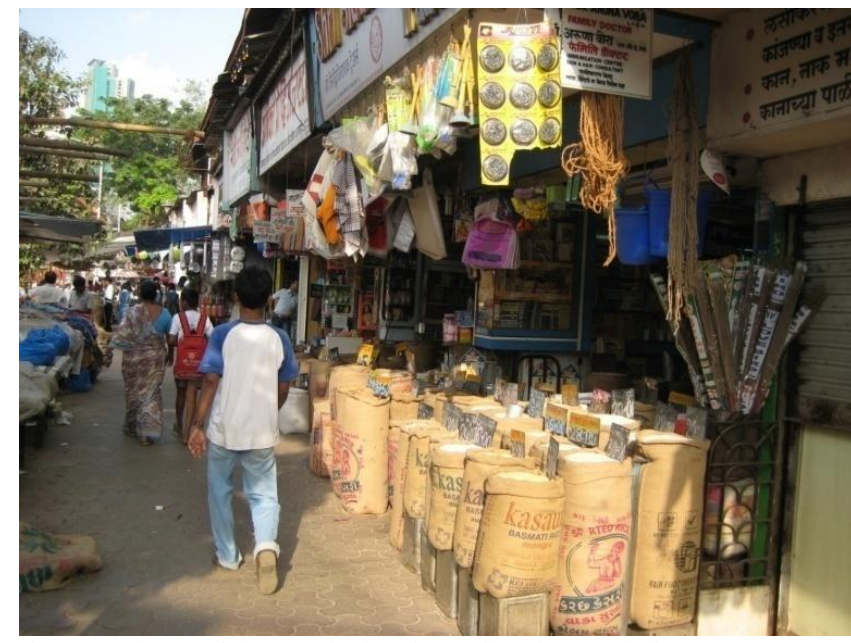

Fig. 4. A cluster of three typical grain retailers in Mumbai

more transportation and logistics than necessary. This motivates our service concept of distributed sub-hubs or subAPMC markets to streamline the supply chains.

\section{A New Operational Concept}

As mentioned earlier, the solution proposed for streamlining the supply chains has three pillars: cloud computing, distributed hubbing and "consumer visible" branding. In this section, we briefly describe an operational concept as a solution to the streamlining problem and focuses on the two non-IT pillars. The IT pillar, i.e., cloud computing, will be discussed in detail in the next section.

We observed that, except the Basmati rice (a special variety of rice), there are few "consumer visible" brands for grains, if at all. Currently, purchasing good-quality grains requires screening out low-quality products, and such a task is performed by the retailers' purchase brokers, who poke grain bags with a sharp metal scoop to collect samples. Consumervisible branding in India is being developed to some extent; the current burgeoning supermarket chains carry their own "brands" of "loose grains," put them in barrels, and sell them by weight. This concept of consumer-visible branding, when implemented with other procedures and standardized 
practices, can help address the quality issues and eliminate the major function of quality screening currently served by the brokers between the retailers and the wholesalers. As mentioned earlier, if information about the "private brands" marketed by the wholesalers to the middlemen can be made available to the retailers or the general public by ICT, this middleman function can also be drastically reduced, if not completely eliminated.

Transportation accounts for a large percentage of the supply-chain cost. It is also a major source of green-housegas emissions. The concept and practice in India of having only one centralized location in a city set aside to enable direct interaction between farmers and retailers dates back seven hundred years. These days, this location is the APMC. Although well-intentioned, such direct interaction rarely takes place, and farmers or retailers cannot afford the time to staff a counter at such a location. In addition, since grains are mostly grown in states in northern India, there are no grain farmers in or near Mumbai or most large Indian cities, and there is never any interaction between grain farmers and retailers there. Such a centralized location has now become, by law, the only location where grain and produce wholesale can take place and the hub to which all grain shipments from millers must terminate and from which all grain shipments to retailers must start. With only one centralized hub location for wholesalers to distribute grains to their retailer customers, the total distance traveled by the distribution trucks is several times than what would be required had there been multiple sub-hub locations. In large cities like Mumbai, the APMC are most likely located in the suburb or in a neighboring city. In such a case, the total distance traveled could even be higher. Concomitant with the unnecessary distance traveled are the unnecessary fuel burn, the resulting environmental impact, traffic congestion, and all the negative consequences associated with the congestion. We conducted a study to demonstrate that a distribution system consisting of four small "sub-hubs" could drastically reduce the total distance traveled by the distribution trucks and reported the findings in [4]. In the rest of this section, we briefly summarize the findings.

Figure 2 provides a bird's-eye view of the Mumbai metropolitan area, consisting of the Mumbai peninsula and Navi Mumbai. Note that the purpose of that study was not to suggest a new distribution system for Mumbai. Rather, it was to inform the designers of possible future grain-distribution systems of other large cities so that the transportation cost can be minimized, subject to non-logistics considerations.

The total cost of transporting grains from the source to Mumbai retailers consists of long-haul cost and distribution cost. We focus on transportation cost first and then address the facility costs, particularly the fixed costs associated with construction and operations of the hub or sub-hubs. Grains are produced in northern states of India, with the state of Punjab being a major grain producer state of India and the primary supplier of grain crops to Mumbai. Since Punjab is directly north of Mumbai metropolitan area and Navi Mumbai's latitude is at the mid-point between the latitudes of the northern and southern tips of the metro area, the total longhaul transportation cost associated with the current system should be approximately the same as its counterpart associated with the alternative four-sub-hub system. The distance traveled by distribution trucks was used as the proxy for the distribution cost.

The results are summarized in Table I. Note that the large ratio 4.86 of the total distance traveled under the four-sub-hub configuration over its current one-large-hub configuration points to a potential of drastic reduction of the recurrent cost of distribution. As for the fixed costs, the issues of land availability and traffic intensity associated with accommodating a large hub in a big city like Mumbai may be much more difficult to resolve than their counterparts associated with accommodating four small sub-hubs. We hope that this drastic numerical evidence will facilitate considerations for governmental policy changes.

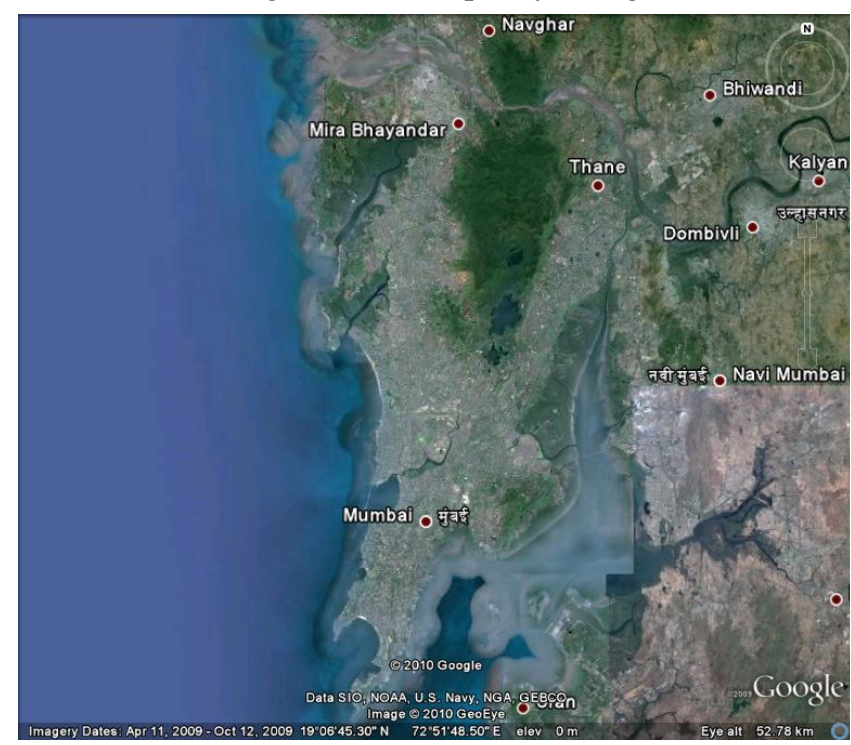

Fig. 5. Mumbai Peninsula and Navi Mumbai.

\section{ICT LEAP-FROGGING ENABLED BY CLOUD COMPUTING}

As mentioned earlier, a broker between a wholesaler and a retailer serves three major functions. One of them is quality checking, which was discussed in the previous section and has the potential of being automated with ICT. The two other

TABLE I

CONTRAst Between the TOW Systems: Distance Traveled $($ TRUCKLOAD $=20$ TONS $)$

\begin{tabular}{|l|r|r|r|}
\hline Region & $\begin{array}{l}\text { Distance to } \\
\text { sub-hub }\end{array}$ & $\begin{array}{l}\text { Distance to } \\
\text { APMC }\end{array}$ & $\begin{array}{l}\text { APMC/ } \\
\text { Sub-hub }\end{array}$ \\
\hline North West & 134.5 & 627 & 4.66 \\
\hline North East & 136.0 & 417 & 3.07 \\
\hline Central & 65.2 & 479 & 7.35 \\
\hline South & 74.8 & 473 & 6.32 \\
\hline All 4 Regions & 410.5 & 1996 & 4.86 \\
\hline Truckload-KM & 862,050 & $4,191,600$ & 4.86 \\
\hline
\end{tabular}


major functions served by the broker, namely checking prices offered by many different wholesalers and making advance payments to wholesalers, pertain directly to information technology (IT). Although India is well known for its IT industry, a large portion of the general public, particularly small merchants like grain retailers, may not have the required financial means and knowledge to acquire, install, operate, maintain, trouble-shoot and upgrade the IT hardware and software. We believe that the modern concept of cloud computing may work particularly well for India, particularly for the grain retailers. Although the concept of cloud computing originated in developed countries to deal with the issues of too much data (to be stored on personal or corporate computers), too much computing, sporadic computing needs, fast growth of computing needs, and/or to support the new paradigms of software as a service (or software on-demand), platform as a service or infrastructure as a service, it may be more beneficial to emerging economies like India. This is because countries like India can leap-frog the developed nations in use of cloud computing and avoid the financial investments and computer savvy that are required for the historically intermediate and incremental steps involving personal computing, particularly the ownership of computing hardware (stand-alone or networked personal computers) and ownership of client-side software.

Retailers in India or other small merchants can benefit from the wealth of information that could be posted on the internet, particularly the prices offered by various wholesalers, and from online payment. Note that India is on its way to catch up with the developed nations in telephony by skipping, i.e., leap-frogging, the step of land-line telephony and capitalizing on wireless communication, via cell phones. As mentioned earlier, while market penetration of land-line telephony in India is approximately $18 \%$ at this point after decades of deployment, its counterpart for cell-phone use has risen to over $50 \%$ in just 10 years. We stress that such leap-frogging may and should take place in computing or internet use in India and other emerging economies, first in individual special economic sectors and then in the larger society as a whole.

\section{A. Service Characteristics}

The key is to require user-friendly, fast and inexpensive price-checking and payment functions. From the perspective of a retailer, the services are provided via the internet. Therefore, the key business model must be at least the Application Service Providers (ASP) model, without requiring anything beyond a so-called "thin client." In fact, what is really needed is a so-called "web-terminal," which can be viewed, in terms of functionality, as a "dumb terminal" plus an internet browser. With such web-terminals, the grain retailers can access internet service applications via a landline or wireless communication. Of course, a traditional desktop or laptop computer with internet access will serve the purpose as long as the concomitant capital and knowledge requirements pose no issues. From now on, we focus on the minimum requirement in terms of both capital cost and technical knowledge. Note, however, that a desktop- or laptop-based solution may work very well through sharing among individuals or through paid use of such hardware at a commercial facility, e.g., an internet café.

These web-terminals have also been referred to as "webenabled" personal access devices in the US and other developed nations. Actually, the devices are not required to be "personal"; the retailers can use shared web-terminals devices to access the internet, as long as the sharing is convenient, economical and secure. To avoid confusion, we will use the term "web-terminals" to summarize the type of devices that are really needed.

From the service provider's point of view, software-as-aservice is required at the outset. As the business of such a provider grows, the provider may benefit from platform-as-aservice and infrastructure-as-a-service. In addition, as the service sector grows, such service systems must be scaled up and the services may be deployed on a private, community, public or hybrid cloud [15,16], reaping the benefit of scalability of cloud computing.

Making payment online or even through a cell phone is commonplace in India, although it is more popular among affluent and technology-savvy people. The system requirements for supporting this function are already well established and documented, and we will focus on information needed by the retailers for their own online pricechecking and about their ability to recognize the private brands offered by wholesalers directly. In fact, the price is set for an individual private brand.

A wholesaler brands its merchandise according to several criteria. Although grain variety is a major and obvious criterion, there exist other major ones. Within a particular grain variety, some consumers prefer grains grown in particular regions. Some consumers prefer surprisingly rice grains that have been in storage for a significant amount of time, as long as the quality is not compromised. A rationale is that the level of water contents of such grains is reduced and therefore the rice when cooked is more "fluffy and "puffy." Such grains may also weigh less and may be perceived as less costly. Quality is of course another major criterion. The quality of the grains arriving at the storage of a wholesaler depends not only on the quality of the same grains when leaving the milling plant but also on the transportation process, through which the grains may be subject to quality deterioration caused by excessive moisture, high temperature, and insect and pest contamination. Different brands may reflect not just the varieties of the grains but also the quality levels. Information about all these brand criteria and the corresponding prices can easily coded in a database for browsing or search.

We assume that the services provided require mostly display of text and hence that the transmissions of text require small communication bandwidths. We next discuss two possible implementations, one with a land-line and the other 
without it but with wireless communication, regardless whether the use is shared or personal.

\section{B. Assessment of Hardware and Software Requirements for Land-line Access to the Internet}

The data-transmission rate for a typical telephone land-line in India is $46.6 \mathrm{kbps}$. It is ample for the retailers' needs for price checking and payment. Higher bandwidths are available and inexpensive. For example, the cost for broadband typically consists of a Rs. 300 monthly charge and a Rs. 3000 one-time charge ( $\$ 1 \cong$ Rs. 46). These should not be considered expensive by most retailers.

In the US and other developed nations, there do not seem to exist well-known brands/models of web-terminals that are used exclusively with land-line telephony. This may have been because the near-ubiquitous presence of desktop or laptop computers in businesses or even homes. The existence of such brands/models for wireless communication, as to be discussed below, may very well have resulted from the market for "mobile internet."

The basic requirements for a land-line-based web-terminal are simple. It consists of a monitor (for user interface), a communication device (hardware and software), and a browser (for display of and request for internet information). These days, computer monitors are well known to be very low-cost and highly reliable. So are the basic communication devices. Browser software is basically free. As a result, a land-line-based web-terminal should be very inexpensive and highly reliable, easing the capital and knowledge requirements to the minimum.

\section{Assessment of Hardware and Software Requirements for Wireless Access to the Internet}

Several well-known brands/models for wireless (mobile) web-terminals already exist in the US or other developed nations, although they are quite high-end when compared to the needs of the grain retailers. They include iPod, iPod Touch, Blackberry, Geode WebPAD, etc. Other brands/models also come with wireless voice communications, e.g., iPhone. A patent has been granted for a wireless web-terminal design that uses land-line through the base station of a cordless-phone. The rate of data transmission for typical basic cell phone in India is $10-30 \mathrm{kpbs}$. It is quite adequate for the retailers to check prices and make payment. If more bandwidth is required, a $256 \mathrm{kbps}$ broadband connection can be purchased with a Rs. 3500 one-time charge and a Rs. 300 monthly minimum.

As indicated earlier, these brands/models have been developed for high-end consumers and may have much functionality that is not needed for our purpose here. The minimum requirements for a wireless web-terminal are similar to those for the land-line counterpart. One strategy is to reduce unnecessary functions of the high-end models just mentioned. However, another strategy is to capitalize on the functions already residing on a basic cell phone. One approach is to develop a "docking station" on which a basic cell phone can be placed and which is connected to a monitor for more user-friendly user interface.

\section{Enabling Non-users of IT to Reap Benefit of Internet}

The concepts proposed in this section may be applicable for other small merchants in India. They may also be applicable elsewhere. Given the security issues legitimately concerning IT managers of large corporations as well as the legacyinvestment issues, many experts pointed out that the first adopters of cloud computing might not be big corporations but might be small to medium enterprises. Some even pointed out that a major contribution of cloud computing may be to attract current non-users of internet to become users. Russ Daniels, HP's CTO for Cloud Services Strategy, stated [15], "...we can make technology useful for a much broader group of people. It's not just consumers, but it's the people that today are nonconsumers, the people that aren't using technology because it's too complex, too expensive, too hard to get to, and that's really exciting...." Franco Travostino (Distinguished Architect of eBay) stated [15], “... I would say that entrepreneurs and small operations have to be the first beneficiaries given that clouds today don't have five-nine [99.999 percent] or seven-nine [99.99999 percent] dependability. Increasingly, we should see more of the Fortune 500 companies. They will be torn between using their own internal cloud within their own IT confines versus a real external cloud by an external provider which they do not have control over. ..."

Note that internet-browsing capability has been or can be added to other common electronic devices, e.g., TV. This bodes well for web accessibility by the retailers and for more streamlined grain supply chains in India.

With the internet browsing capability of web-terminals, cell phones and the other common electronic devices discussed in this section, no conventional computers, either desktop or laptop computers, are required. This enables emerging economies' leap-frogging of developed nations in the sense that emerging economies can skip the expensive stages of stand-alone computing, client-server computing, software as a service, hardware as a service and infrastructure as a service directly to the drastically more efficient cloud computing. Privacy and some other issues associated with the use of cloud computing in developed nations may not be as important in emerging economies, at least comparatively.

\section{Cloud Computing And ICT For The EnTIRE Chains}

In this section, we discuss briefly how cloud computing and ICT may significantly improve the operations of the rest of India's grain supply chains and how the potential improvement may address some critical and urgent issues facing the Indian society as a whole.

Recently, India's economic and thereby the political landscape has been rocked by high food inflation, which has been on the order of $17 \%+$ in recent past. Several reasons have been put forward for this state of affairs. A key set of 
reasons revolves around inefficiencies in grain-food supply chains and low levels of visibility in the supply chains.

We now briefly discuss the portion of grain supply chains on the farmer's side. If the farmers have direct access to information about different prices offered by the traders/consolidators for the same commodity in the same or different APMCs and, for that matter, even have access to such information at the regional level, they can accordingly choose to sell the commodity in the 'right' market at a 'right' time and get a better price. This information can be made available directly to the farmers by way of providing them access to different information bases on the web. Such access to information can be made possible in a ubiquitous way by way of cloud computing, web terminals and the almost ubiquitous wireless connectivity.

In a similar fashion, the next set of traders in the supply chains and finally the very large wholesalers will stand to benefit if they have access to details about the crop planting and yield on a macro-scale. These details can include information like approximate size of area in which a particular crop (e.g., wheat) has been planted, the likely availability of the final crop to be sold at different APMCs in different parts of the country in different timeframes, and the progression of the commodities and their quantities through the supply chains. Such information in turn can be used to project availability of different commodities to be sold in different parts of country in different time frames. Another significance of this information is that the retailers and the wholesalers from which the retailers source different commodities will have a much better insight into supply of commodities and their quantities at different points in time at different relevant locations.

This transparency, i.e., the "visibility in extreme," will enable and encourage the stakeholders to trade and make commodities available at "fair market prices." Their trading decisions will be much more informed. The central point is, cloud computing, web terminals and wireless access enable this information to be universally available. Of course the information databases need to be made available on the cloud for easy access by the stakeholders.

Currently the prices at which the commodities are traded are lot more arbitrary and cannot be called "well informed". The small traders and their customers stand to lose most because of this state of affairs. Moreover, these prices are highly influenced by "dynamics" of the Commodity Exchange (MCX). It appears that a small group of traders on the exchange can have a high degree of influence on the price at which a particular commodity is traded, which in turn impacts the retail price of the commodity, hurting the customers.

A key assertion of this paper is that the unfair pricing which can be determined by improper or even speculative means can, to some extent, be neutralized by universal cloudcomputing-based agricultural databases and wireless access to them.

\section{SUCCESS AND HINDRANCE FACTORS}

In this section, we discuss possible success and hindrance factors for implementation of the proposed use of cloud computing in India's grain supply chains. Note that although our proposal to post the price information on the internet was motivated to replace a service currently performed by the middlemen between the wholesalers and the retailers, the information is perhaps more useful for the consumer and the APMC. We first discuss factors that would facilitate the implementation and then factors that may hinder the implementation.

\section{A. Possible Success Factors}

As pointed out earlier, APMC of a city plays a pivotal role in the operation of grain supply chains. A primary goal of APMC is to ensure market efficiency in general and to prevent price gouging in particular. Mr. Sudhir Tungar, the Principal Secretary of Mumbai APMC, informed us during an interview of a recent success in detecting and resolving a price-gouging incident in the district of Colaba in South Mumbai. Local retailers told their customers about a nonexistent crop shortage and charged prices that were about five times the prevailing wholesale prices charged at the Mumbai APMC approximately only $36 \mathrm{~km}$ away. APMC sent truckloads of the merchandise to the district immediately after detection. The public apprehension immediately subsided, and the price gouging ceased. He also informed us that the large price mark-ups might also result from retailer speculation about supply volatility. Had wholesale prices or the prevailing retail prices been posted on the internet, price-gouging incidents like this one would not have occurred. An informal survey of our colleagues and some students confirmed our conjecture that most grocery shoppers in India really want to know a fair price range for each major staple grain, pulse (e.g., beans) or vegetable. In addition, major success factors for eChoupal include the farmers' strong desire to know fair price ranges for their crop and the ability of eChoupal to provide the information [14]. We believe that APMCs' and consumers' desires for transparency in price information will help propel the realization of the proposed use of cloud computing via a web-terminal.

It should be informative to discuss successful implementations of cloud-computing-based or closely related initiatives or in India. eChoupal was developed when the client-server architecture was the state of the art in India. More importantly, it relies on expensive communication with rural farmers, via landline or microwave, for downloading educational video and other services requiring substantial bandwidth. Although client-side software may be necessary, the service can be considered cloud computing. It is conceivable that this internet-based service can be provided via a web-terminal, i.e., its resident browser, if the communication bandwidth is sufficient and advanced video technology is employed. The more important things are the value of price information to farmers and the farmers' 
willingness to pay for the information; they have helped propel the demand for and the success of eChoupal. Upton and Fuller [14] detailed how and how much farmers have benefited from the transparency of the price information. We believe that their counterparts on the consumer side will help propel the implementation of the proposed use of cloud computing.

Farmer lobby is very large and politically strong. Therefore, anything that can help farmers improve their livelihood becomes a favorite cause for many politicians. For example, in a recent budget, the Central Government of India pardoned a large part of rural agricultural debts. Farmers have complained about the extortionate service charges piled on their meager crop revenues for decades; so have the consumers. Streamlining any portion of the grain supply chains will benefit the farmers and the consumers. Therefore, we believe that, in terms of political support, the proposed cloud-computing-based operational concept on the consumer side will be popular for the society at large.

As for price information on the consumer side of the supply chains, Indian Harvest [17] currently provides daily spot prices of various agriculture commodities, but only for several commodity trading centers in India. Our goal is to develop a feasible and attractive operational concept that can be implemented in the near term to provide informational transparency on the consumer side and hence complement eChoupal in streamlining India's grain supply chains.

We now turn our attention to successful implementation of cloud-computing-based initiatives on the consumer side of grain supply chains in the US. This portion of the supply chains has long been fully integrated and dominated by few large supermarket chains, e.g., Safeway. The kind of wholesalers and retailers currently in operation in India have long disappeared in the US. As a result, the streamlining issue being dealt with in this paper does not exist in the US, and there are no comparable initiatives currently or in the recent past. For decades, US supermarket chains have had their own internal MIS and IT departments. With the deployment of advanced technologies like virtualization, the IT currently supporting this portion of the supply chains can be characterized as a private cloud or an "internal cloud" managed by a centralized internal authority [1].

Current US searchable/queryable agriculture databases are mostly implemented as cloud computing, with search or query requests specified and transmitted through an internet browser (without any other client-side functionality) and with the searches or queries performed in the cloud, free of charge. We give several examples for such agriculture databases to demonstrate their technical feasibility and popularity.

The internet service provider agriculture.com [18] provides daily and intraday price data; agricommodityprices.com [19] provides periodically updated commodity-specific and country-specific price data. We note, however, that other databases exist but some of them have been provided mostly for research purposes, instead of for making routine purchasing decisions. An example is the database provided by the Food and Agriculture Organization of the United Nations. In particular, FAOSTAT [20] provides time-series and cross sectional data related to food and agriculture for some 200 countries, and PriceSTAT [21] supports queries for the annual average price for a commodity, e.g., Rice (Paddy), in a country, e.g., India. The National Agricultural Statistics Service (NASS) of the US Department of Agriculture maintains a similar database, but with a focus on the US and with more details [22]. www.indexmundi.com [23] provides average monthly prices of rice and other commodities of a country, among a large amount of data constituting a country profile.

Most major supermarket chains in the US publish their prices on the internet (i.e., in the cloud) and some of them even take online orders for home delivery or pick-up at store. All these support our key assertion that the unfair pricing can, to some extent, be neutralized by universal, cloud-computingbased agricultural databases and wireless access to them.

\section{B. Possible Hindrance Factors}

We now discuss possible factors that may hinder the implementation of the proposed cloud computing initiative. Although it is possible that retailers may be unwilling to use computers or "web-terminals" to access price information posted on the internet, we believe that it is not likely. There has been no particular resistance to usage of computers in India even in rural areas - particularly when there is a good reason to use it. Computer training institutes imparting the basic computer skills (e.g. office, basic programming, basic maintenance skills) are ubiquitous even in C, D class cities and smaller towns because they are so popular and in demand.

Let us address the more general possible issue of resistance to technology adoption. There are no better examples than those involving rural populations. There are several instances where rural populations have adopted technology without much resistance, with adoption of Automated Teller Machine (ATM) being a simple example. While the fishermen of the Indian state of Kerala are returning from their fishing trips, they make cell-phone calls to check prices offered at different on-shore markets and decide on their landing spots accordingly. This also shows a strong desire for price information. In addition, basic information access is possible and inexpensive with no-frill mobile phones and of course with wireless-internet connected thin clients. The price of a mobile phone supporting GPRS-enabled internet connection is approximately Rs.3000, with an approximate GPRS (general packet radio service ) connection cost of Rs.100 per month (with unlimited usage). In general, we do not see any real resistance to technology, per say. As long as the technology provides value and is easy to use and afford, it will be embraced by the target users.

Currently, cellular telephony covers over $90 \%$ of the 1 billion Indian population, with over 700 million subscribers. Even if the proposed cloud-computing-based initiative 
experiences initial resistance to use of web-terminals or computers, basic price information can be obtained and payment can be made via a regular cell phone. Internet searches or queries made via cell-phone text messaging have long been supported, e.g., Google SMS Applications [5]. Google SMS Search [6] can be used to get information on driving directions, sports, movies, stocks, definitions, etc; these services are free from Google but message \& data rates may apply. Note that the required technology is the regular wireless telephony, not the newer and more expensive $3 \mathrm{G}$ or $4 \mathrm{G}$ technology. Note also that we are not suggesting the use of SmartPhones for accessing the internet. They are very expensive to begin with and are marketed for affluent and technology-savvy users. Also, many applications, i.e., the "Apps," require significant client-side functions.

We now address the possible resistance to the proposed cloud-computing-based initiative from the wholesalers, the retailers and the middlemen. A retailer we visited informed us that his family and the family of his procurement agent (i.e., middleman between him and the wholesalers at the Mumbai APMC) have cooperated for generations. As long as he can make a reasonable profit, whether his agent makes a lot of profit or not does not really concern him. Although he has not felt any urgent need to find an alternative way of securing grains, he would be happy to try out the prototype technology and user interface we planned to develop. As mentioned earlier, the proposed information transparency can also prevent retailer price gouging. It can also introduce or at least encourage fair competition among local retailers. These may not be welcome by the middlemen and retailers alike. However, as discussed earlier, we believe that demand for informational transparency by the consumers, the farmers and APMC officials may entice or even force changes required for streamlining the grain supply chains of India.

Resistance from middlemen is expected. Possible replacement work for them include quality inspection, certification or assurance for the supply chains. However, the work would not be performed for individual retailers on specific retailer purchases but perhaps for APMC or a certification body. As for the threats to existing traders (not just the middlemen between the wholesalers and the retailers) and trading relationships, these problems have been overcome before, e.g. by eChoupal. ITC, the sponsor of eChoupal, has found new roles for commission agents and has successfully managed any potential resistance from them.

\section{LEAP-FROGGING FOR THE ENTIRE SOCIETY IN GENERAL}

Technical merits of a technology alone cannot guarantee its market success; technology deployment and management of technology is a critical issue. Although cloud computing was not invented for emerging economies, e.g., for the need of overcoming barriers against internet access by people without affluence or computer savvy, it does present many opportunities for emerging economies. The transportation sectors of developed nations have experienced a similar situation in the past two decades. Advances in computing, communication and automation technologies spurred a intense level of interest in applying the technologies to improve transportation systems. A discipline called Intelligent Transportation Systems (ITS) emerged. Many application possibilities, called user services, were developed and studied. Some initiatives originally regarded as the most promising ones failed miserably, due to inattention to deployment issues. These failures as well as the necessity to streamline many concurrent research and development efforts and to minimize risks, a framework for organizing the many deployment issues at the outset of research and development was developed [24]. Developing such a framework for application of advanced computing technologies to emerging economies may be a worthy research topic.

Cloud computing can enable an entire society to take advantage of the economic benefits. This applies not only to the urban and suburban areas that have access to highbandwidth Internet access, but also to the remainder of the developing world that have minimal connectivity to the rest of the world. In this section, we first deal with these two crosssections of society and deal with the independent issues that are relevant to each of them. We then point out the leapfrogging opportunity offered by the concept of internal cloud to replace desktop or laptop computing or skip it all together and discuss applications of cloud computing in other sectors of the Indian society.

\section{A. Areas with High-bandwidth Internet connections}

Societies with high-bandwidth Internet connections, particularly the developed nations, use cloud computing with two specific aims: first, to reduce the cost of application development; and second, to avail of services that have costs that are lower than that built from traditional delivery means. The lower service costs result mainly from a new service delivery and charging paradigm for software applications. For urban and suburban areas of an emerging economy, the costs of accessing various software services can be further reduced due to reduced infrastructure and development costs, if the kind of web-terminals discussed in Section 4 are used. Note that the infrastructure costs include those incurred for needs assessment, system specification, equipment selection, purchase, installation, maintenance, upgrade, repair, security, and many other life-cycle concerns. Assessing overall cost savings achievable via this leap-frogging is a critical research issue for emerging economies. This research was never needed in developed nations and hence has not been paid any attention. As discussed earlier, the lower requirements for hardware and software knowledge associated with cloud computing are another main source of benefits that emerging economies can fully capitalize on. Although the benefit of lowered knowledge requirements on accessing the internet is much more intangible than the benefit of lower costs, 
assessing this benefit is also an important new research subject.

Lower cost of application development allows providers to bring applications to the market much faster than what was possible previously. This allows a larger segment of the population and even individuals to contribute applications to the ecosystem, while previously this was the domain of medium to large software houses. We can illustrate this by looking at the costs of two Cloud providers. As summarized in Table II, Google App Engine provides a lot of free resource time for application developers - these free resources can be used to mitigate the cost of application development. In addition, Google App Engine provides development tools for free.

In addition to these free resources, cloud providers such as Microsoft Azure and Google App Engine provide low development and hosting costs for cloud applications beyond the free time. See Table III for a comparison.

The next logical step is to compare these costs to that incurred by those using traditional development means. Assuming that medium to large software houses have consolidated their operations in a mid-size data center, researchers at the RAD lab in Berkeley have examined costs and found that the infrastructure costs in a large cloud data center virtualized to different application developers are five to seven times lower than that in the mid-size data centers used by the software houses. This gives a tremendous advantage to the next wave of application developers who are not burdened with the cost of maintaining these mid-size data centers.

These translate to lower cost of goods for cloud services developed as a result. Researchers have audited financial statements to examine claims that service-oriented architecture

(SOA) leads to higher profits relative to traditional software delivery models [25]. Specifically, they have examined vendors that rely on the Software-as-a-Service (SaaS) pricing model, and compare their performance to other firms that still use the traditional perpetual license model. The researchers

TABLE II

FreE DEVElopment ResourCES IN GOOGLE APP ENGINE

\begin{tabular}{|l|l|}
\hline Category & Free Resource (Daily Rate) \\
\hline CPU & 6.5 hours \\
\hline Bandwidth out & $1 \mathrm{~GB}$ \\
\hline Bandwidth in & $1 \mathrm{~GB}$ \\
\hline Storage (database) & $1 \mathrm{~GB}$ \\
\hline Storage Transactions & 10 Million \\
\hline
\end{tabular}

find that, relative to their peers, SaaS firms tend to have lower costs of goods sold as a portion of revenues.

Even non-traditional scientific applications get an economic benefit from running in the cloud, which could bolster scientific development in developing nations. Kondo et al. [26] did a survey of grid computing applications for scientific processing and tried to determine the cost-benefits
TABLE III

Development Resources Cost in Microsoft Azure And GoOgle APP ENGINE

\begin{tabular}{|l|l|l|}
\hline Category & Windows Azure & Google App Engine \\
\hline CPU & $\$ 0.12 /$ hour & $\$ 0.10 /$ hour \\
\hline Bandwidth out & $\$ 0.15 / \mathrm{GB}$ & $\$ 0.12 / \mathrm{GB}$ \\
\hline Bandwidth in & $\$ 0.10 / \mathrm{GB}$ & $\$ 0.10 / \mathrm{GB}$ \\
\hline Storage (database) & $\$ 0.15 / \mathrm{GB} /$ month & $\$ 0.005 / \mathrm{GB} / \mathrm{month}$ \\
\hline Storage Transactions & $\$ 0.01 / 10,000$ & Not Available \\
\hline
\end{tabular}

of cloud computing versus volunteer computing applications. The authors calculated overhead for platform construction, application deployment, compute rates, and completion times. Given a best-case scenario, the authors found that the ratio of volunteer nodes needed to achieve the compute power of a small Amazon EC2 instance is about 2.83 active volunteer hosts to 1 .

One potential drawback of cloud computing is that complex graphical tasks need dedicated computing power on a desktop machine with a powerful GPU. In such a scenario, these applications would not lend themselves to cloud computing and potentially increase development costs in emerging economies. However, even in such a scenario, the advent of multi-core GPUs may enable virtualization of resources for cloud computing users and allow them to avoid traditional application development costs. Lin and Wang [27] have proposed a cloud computing framework for such domains, with the end users only has a relatively inexpensive thin terminal with a high resolution screen and I/O devices.

\section{B. Areas with Limited Connectivity}

Although such leap-frogging is quite feasible for urban and suburban areas now or in the near future, where access to the internet is already prevalent and hence is not a big issue, significant challenges exist now for such leap-frogging to take place in rural or remote areas due to low accessibility to the internet. However, we argue that similar leap-frogging directly to cloud computing should still be the goal because it should be much less costly than going through the stage of personal computing and the other traditional computing architectures.

This points to a critical area for researchers to enable direct realization of the cloud computing paradigm in this section of society. We again remind the reader of the analogy between IT leap-frogging and telephony leap-frogging. With the advent of wireless-communication technology, not only is there much less need for further development of costly wired telephony, the strategy for further developing telephony and the resulting hardware/software architecture can be revamped to fully capitalize on the wireless technology. In the realm of IT, the IT development strategy and architecture for rural or remote areas of an emerging economy can be revamped in a similar way. A critical research subject is how to allow efficient access to the internet or the cloud in rural or remote areas of an emerging economy without the equipment required in the conventional architectures through which the 
cloud computing evolved in developed nations. More precisely, how can such access be enabled without PCs and laptops? Note that this issue has not been tackled by the developed nations because owning PCs, laptops, tablet computers, smart-phones and other advanced devices has not been and will most likely not be an issue. The reader is again reminded that in addition to costs, knowledge requirements are another major challenge for access to the cloud in rural and remote areas of an emerging economy. The examples given below tackle these issues with actual research projects in developing economies and use innovative techniques to bridge the knowledge gap.

Furthermore, looking at the past, one can look to the evolution of the PC industry as an example of how hardware costs and knowledge gaps can be overcome. The concept of personal computing did not truly exist until Apple introduced the Macintosh in 1984 - a computer that got rid of command prompts in favor of a graphical user interface. The Macintosh did not require a huge learning curve like previous DOS command-line driven machines. For the first time, computers became usable by normal people - not just the professionals. Microsoft learnt from this new concept of graphically-driven computing, following up with Windows in 1986, broadening the market so that almost everyone can afford a computer from different hardware manufacturers in developed nations. By 1995, most households in the US had a PC, and it is not unreasonable to speculate that the combination of wireless and mobile handset technologies can achieve the same for the emerging regions given that already mobile usage has crossed the 2 billion population mark.

A key inhibitor to cloud computing in emerging economies is the absence of connectivity to the cloud. Many developing regions around the world, especially in rural and remote areas, require low-cost network connectivity solutions. Traditional approaches based on telephone, cellular, satellite or fibers have proved to be an expensive proposition especially in low population density and low-income regions. In Africa, even though cellular and satellite coverage is available in rural regions, bandwidth is extremely expensive due primarily to low user densities (satellite usage cost is about US\$3000 per Mbps per month). WiMax, another proposed solution, is currently also very expensive and has been primarily intended for carriers (like cellular). WiMax is hard to deploy in the "grass roots" style typical for developing regions. WiFi-based Long Distance (WiLD) networks are emerging as a low-cost connectivity solution and are increasingly being deployed in developing regions. The primary cost gains arise from the use of very high-volume off the shelf 802.11 wireless cards, of which over 140 million were made in 2005. These links exploit unlicensed spectrum, and are low power and lightweight, leading to additional cost savings. These networks are very different from the short-range multi-hop urban mesh networks. Unlike mesh networks which use omnidirectional antennas to cater to short ranges (less than 1-2 km at most), WiLD networks comprise of point-to-point wireless links that use high-gain directional antennas (e.g. $24 \mathrm{dBi}, 8$ degree beam-width) to focus the wireless signal (for line of sight) over long distances (10-100 km).

To extend this connectivity to a large population of users, the developers of WiLD proposed cellular phones as a medium of connectivity. Cellular communications, including handsets and base stations, have become ubiquitous technologies throughout the developing and developed world. Roughly three billion users spend large portions of their income on these basic communications. However, the remaining half of the world currently has limited access, in large part due to lack of network coverage. Some areas do not have a high enough population density to support a traditional cellular deployment. Other areas are too far from established infrastructure to make a deployment economically feasible. This leads to many rural areas where there is no network coverage at all. To resolve this issue, the WiLD developers propose the Village Base Station (VBTS), which provides four main benefits:

- flexible off the grid deployment due to low power requirements that enable local generation via solar or wind;

- explicit support for local services within the village that can be autonomous relative to a national carrier;

- novel power/coverage trade-offs based on intermittency that can provide bursts of wider coverage; and

- a portfolio of data and voice services (not just GSM).

VBTS is essentially an outdoor PC with a software-defined radio that implements a low-power low-capacity GSM base station. Long-distance WiFi provides "backhaul" into the carrier. At around 20W, its power consumption is low enough to avoid diesel generators and the corresponding requirement for roads and fences. This also reduces the operating costs significantly. The base station can be deployed in the middle of the village, on a nearby hill, or in any other area with lineof-sight coverage. Although much of the contribution of VBTS is engineering the combination of a software radio, WiFi backhaul, and local generation, there are two main societal contributions:

- the development of a platform for a wide range of services

- the optimization of coverage versus power consumption via variable power and intermittent coverage

The connectivity has led to the development of unique solutions for the general population, one of which covers the field of education. English is the language of power in India associated with the middle and upper classes. In other developing regions, it is another language such as Spanish, Mandarin, or French which is not native to most of the population. The public school systems in developing regions face insurmountable difficulties. In India, for example, it has been consistently difficult to converse in English with those teachers responsible for teaching English in poor schools, where the overwhelming majority of children in the country struggle to learn. More important, public schooling is out of 
the reach of large numbers of children in rural areas and the urban slums who cannot attend school regularly, due to their need to work for the family in the agricultural fields or households. At the same time, cell phones are increasingly adopted in the developing world, and an increasing fraction of these phones feature multimedia capabilities for gaming and photos. These devices are a promising vehicle for out-ofschool learning to complement formal schooling. In particular, the English learning games on cell phones present an opportunity to dramatically expand the reach of English learning, by making it possible to acquire ESL in out-ofschool settings that can be more convenient than school. Games can make learning more engaging while incorporating good educational principles. More important, a large-scale evaluation with urban slums children in India has shown significant learning benefits from games that target mathematics. The developers of the English learning project believe that similar outcomes can be replicated with elearning games that target literacy. The challenge in evaluating any language learning project, however, is that the language acquisition is a long-term process on the learner's part. Worse, with a novel technology solution that has yet to be institutionalized, there are tremendous logistical obstacles in running a pilot study over a non-trivial duration. After 3 years, in which the developers commenced with needs assessments and feasibility studies, followed by subsequent rounds of field testing interleaved with numerous iterations on our technology designs, they have established the necessary relationships with local partners for such an evaluation.

Another approach to connectivity in emerging economies is the shared usage of scarce networking bandwidth. Computer scientists in Pakistan are building a system to boost download speeds in the developing world by letting people effectively share their bandwidth. Software chops up popular pages and media files, allowing users to grab them from each other, building a grassroots Internet cache. In developing countries, almost all the traffic leaves the country. That's the case even when a Pakistani user is browsing websites hosted in his or her own country. The packets can get routed all the way through a developed nation and then back to a developing country. So a team in Pakistan is developing DonateBandwidth, a system inspired by the BitTorrent peerto-peer protocol that is popular for trading large music, film, and program files. With BitTorrent, people's computers swap small pieces of a file during download, reducing the strain placed on the original source. DonateBandwidth works in much the same way but lets people share more than just large files. When users try to access a website or download a file, a DonateBandwidth program running on their machine checks first with the peer-to-peer cache to see if the data is stored there. If so, it starts downloading chunks of the file from peers running the same software, while also getting parts of the file through the usual Internet connection. The software could allow people in countries that have better Internet connections to donate their bandwidth to users in the developing world.
DonateBandwidth also manipulates an ISP's cache. When running DonateBandwidth, a computer starts downloading part of a file, while also sending a request for other DonateBandwidth users who have access through the same ISP, and whose computers have spare bandwidth, to trigger them to start downloading other parts of the same file. The file is then loaded into the ISP's cache, so it can be downloaded more quickly. The project is similar to distributed computing schemes such as SETI@Home, which uses volunteers' spare computer power to collaboratively analyze radio signals from space, looking for signs of intelligent life. DonateBandwidth permits sharing of unused Internet bandwidth, which is much more valuable in the developing world, compared to computing cycles or disk space.

\section{Potential of Internal Cloud for Non-transaction IT}

In developed nations, many transaction-based enterprise IT applications involving large databases have already been or are being migrated from the client-server architecture to cloud computing, particularly internal cloud. The task of such migration is not very difficult because the uses of the applications are already centralized and the primary task is to implement the client-server interaction with the browser technology. However, many organizations in developed nations, and particularly those in emerging economies, whose primary IT needs are not database-oriented transactions can also benefit from use of internal cloud computing.

The main idea is to have all resident software applications (not supported by an external cloud) migrated to an internal cloud, i.e., centralized and virtualized servers. This way, there is no need to have a desktop computer on top of every desk. Just replace every desktop computer with a webterminal. The web-terminals will need virtually no IT support. All the efficiency benefit achievable through an external cloud can be achieved with such an internal cloud, except for the larger economy of scale. Obviously, this internal cloud can be supplemented with access to an external cloud. For example, free software applications for office work are widely available in the internet, if they are not provided in the internal cloud. Such free applications include Google Doc, Google Spreadsheet, etc.

The proposed concept of leapfrogging by means of performing all computing in the cloud and accessing the cloud only through a simple web-terminal can be referred to as 'pure cloud computing' or simply 'pure cloud.' This new term of 'pure' cloud is intended to articulate a new concept of cloud computing and differentiate its minimum client-side hardware and software requirements from the higher clientside requirements of any other cloud-computing implementation. 'Pure cloud' is based not only on cloud computing but even an easier, more easily deployable and therefore more widely acceptable implementation of cloud computing where the prerequisites needed to operate the clients are almost nothing. Only a 
simple browser-based access to the cloud suffices, and it can be supported on thin, simple and low-cost web-clients. This 'pure cloud' concept will be particularly beneficial for emerging economies.

Migration of the non-transaction IT uses to an internal or external cloud may be beneficial for any organization in general but may be particularly beneficial for large non-profit organizations like schools and universities, hospitals, etc. When such migration is implemented in elementary through high schools, in developed nations or emerging economies, potential benefits include not only reduction of hardware, software and labor costs but also increased ability of schools to monitor or even control of proper student access to internet contents. Note that video-game playing and internet browsing unrelated to classroom learning may severely distract students. Other potential benefits include reduced opportunities for equipment theft or damage. More importantly, due to the significantly lower hardware, software and labor costs associated with the proposed internal cloud architecture, schools may finally be able to provide in-class access to computing and the internet.

\section{Cloud Computing for Other Services or Countries}

We discuss in this sub-section cloud-computing-based initiatives in other sectors of India or in other countries. Due to space limitation, we focus on the health industry. After a brief discussion of application of cloud computing in the US, we illustrate leap-frogging opportunities for emerging economies with one project proposal submitted to the Pakistan government and one specific start-up company in India.

It is well known that the US is experiencing a daunting healthcare crisis. Innovative IT has been regarded as a major improvement that can significantly reduce cost and increase quality. Among the better known innovations is the electronic medical record (EMR) or electronic health record (EHR). To facilitate coordination and even direct communication among different healthcare providers involved in the care of a patient, most of the EMR implementations are based on cloud computing, particularly internal cloud.

Cloud-based EMR presents an obvious leap-frogging opportunity for emerging economies. What has not been discussed in the developed nations is the leap-frogging opportunity to "pure cloud," mentioned earlier about exclusive use of web-terminals, in lieu of desktop computers, for cloud access. The first author participated in a threepartner team effort in response to a request for proposals "Establishing Center of Innovation for Use of ICT in Healthcare Sector" issued by the National ICT R\&D Fund of the Ministry of Information Technology of Pakistan. The proposal features the use of cloud computing, including the concept of "pure cloud," as a main theme of the proposed research. The funding decision is yet to be made. After a nearly one-year halt of operations, the National ICT R\&D Fund recently resumed operations [28].
The third author is a co-founder of an Indian company called A3 BioMed Technologies Ltd [29]. The company is in business for providing solutions and services that will enable cardiologists to remotely monitor their patients via mobile phone from anywhere in world. The solutions are based on wireless devices connecting the patient to a server. The company provides services, based on these solutions, to healthcare organizations like nursing homes, small hospitals and hospital chains. In the healthcare industry, patient's privacy, information confidentiality and data security are very important. Also, healthcare organizations are very possessive about their patients' medical records, for good reasons. As a result, each organization wants its own private server. However, many organizations are not able to support (and afford) their own physical servers on their premises and all the operational and management overhead such a private server will entail. This would impede wide adoption of the remote patient monitoring services. However, the cloud server technology comes to the rescue. A3's server software components can be installed on a cloud-based server, and each organization can have its own "private cloud" that is managed by A3 or a third party. Note that, in this architecture, a cloud-based server, including the hardware infrastructure, can be dedicated for exclusive usage by one organization at an affordable cost. So, the cloud-based server technology plays a crucial role in roll-out and adoption of this life-saving remote monitoring technology. Note that such remote patient monitoring is of particular relevance to countries like India where there is a general dearth of qualified doctors and patients residing in vast areas of the country do not have easy access to proper healthcare.

\section{CONCLUSIONS}

In the process of our seeking to streamline India's grain supply chains, we discovered cloud computing to be a promising solution. Cloud computing enables use of computing without user-side hardware, software and the associated financial and knowledge requirements, except for the need of a "web-terminal" and access to the internet. We capitalized on this opportunity and proposed a solution based on cloud computing and other operational concepts for streamlining grain supply chains in India. Design of a prototype system is underway that fulfills the functions currently provided by the middlemen between the wholesalers and retailers, adds value to the retailers, wholesalers and even consumers, and is user-friendly.

In addition to distributed hubbing, "consumer visible" branding and cloud computing, which was the main focus of this paper, many other improvement opportunities exist. Further integration of IT with the supply chains beyond the proposed use of cloud computing on the consumer side and the expanding use of eChoupal.com on the farmer side is critical, e.g., RFID, for this worthy and fertile research area. Another improvement opportunity is to increase the economy of scale. Significant reduction in the current number of 600 
wholesalers may lead to significantly higher efficiency due to not only consolidated wholesale operations at the hub or subhubs but also coordinated distribution. IT may actually play a significant role in such a possible reduction, and this and many other IT studies are worthy subjects for future research.

Assessing overall cost savings achievable for urban and suburban areas, where access to the Internet is not a big issue, via this leap-frogging is a critical research issue for emerging economies.

Another critical research subject is how to allow efficient access to the Internet or the cloud in rural or remote areas of an emerging economy without expensive PCs and laptops.

We believe that many existing operations in other industrial sectors of an emerging economy can benefit from cloud computing in similar ways. In fact, we argued that such leapfrogging can benefit the entire society of an emerging economy.

\section{ACKNOWLEDGMENT}

The guest editor's and reviewers' constructive comments led to a much better paper than the original version and are gratefully acknowledged.

\section{REFERENCES}

[1] P. Mell and T. Grance, "The NIST Definition of Cloud Computing," (2011). http://csrc.nist.gov/publications/drafts/800-145/Draft-SP-800145_cloud-definition.pdf; accessed on July 29, 2011.

[2] Rimal, B.P., Choi, E., and Lumb, I. (2009), "A taxonomy and survey of cloud computing systems," Proceedings of the Fifth International Joint Conference on INC, IMS and IDC, $\mathrm{p} 44-51$

[3] Cleverley, M. (2009), "Emerging markets. How ICT advances might help developing nations," Communications of the ACM, Vol. 52, No. 9, pp. 30 - 32.

[4] Tsao , H.-S. J., Parikh, S., Ghosh, A.S., Pal, R., Ranalkar, M., Tarapore, H., and Venkatsubramanyan, S. (2010), "Streamlining Grain Supply Chains of India: Cloud Computing and Distributed Hubbing for Wholesale-Retail Logistics,"., Proceedings of 2010 IEEE International Conference on Service Operations and Logistics, and Informatics (IEEE-SOLI 2010), Qingdao, China.

[5] Google, http://www.google.com/intl/en_us/mobile/sms/ .

[6] Google, http://www.google.com/intl/en_us/mobile/sms/search/ .

[7] Sachan, A., Sahay, B.S., and Sharma, D. (2005), "Developing Indian grain supply chain cost model: a system dynamics approach," International Journal of Productivity and Performance Management; Vol. 54, No. 3/4. pp.187-205.

[8] Sachan, A., Sahay, B.S., and Mohan, R. (2006) "Assessing benefits of supply chain integration using system dynamics methodlogy," International Journal of Services Technology and Management, Vol. 7, No. $5 / 6$, pp. 582-601.

[9] Dharni, K. and Sharma, S. (2008),'Food Processing in India: Opportunities and Constraints," The ICFAI University Journal of Agricultural Economics, Vol. V, No. 3., The ICFAI (Institute of Chartered Financial Analysts of India) University Press, India.

[10] Singh, R., Singh, H.P., Badal, P.S., Singh, O.P., Kushwaha, S., and Sen, C. (2009), "Problems and Prospects of Food-retailing In the State of Uttar Pradesh (India)," Journal of Services Research, Vol. 8, No. 2 (October 2008-March 2009), Institute for International Management and Technology, New Delhi, India.

[11] ICRA (2001a), Report on FMCG, Investment Information and Credit Rating Agency, New Delhi, India, March, 2001.

[12] ICRA (2001b), The Indian FMCG Sector, Investment Information and Credit Rating Agency, New Delhi, India, May, 2001.
[13] ETIG (2003), Changing Gears: Retailing in India, Economic Times Intelligence Group, Mumbai, India.

[14] David M. Upton, Virginia A. Fuller (2003), "ITC eChoupal Initiative," HBS Case 604-016, Harvard Business School, Harvard University; also in "Corporate Information Strategy and Management" by Applegate, L.M., Austin, R.D. and McFarlan, F.W. ( $8^{\text {th }}$ edition).

[15] Milojicic, D. (2008),"Cloud Computing: Interview with Russ Daniels and Franco Travostino", IEEE Internet Computing, Sept./Oct., 2008.

[16] Youseff, L., Butrico, M., and Da Silva, D. (2008), "Toward a unified ontology of cloud computing," proceedings of 2008 Grid Computing Environments Workshop

[17] Indian Harvest, Centre for Monitoring Indian Economy Pvt. Ltd. http://www.cmie.com/database/?service=database-products/sectoralservices/indian-harvest.htm, accessed on July 30, 2011.

[18] Agriculture.com, http://www.agriculture.com/markets/commodities, accessed on July 30, 2011.

[19] Agricommodityprices.com, http://www.agricommodityprices.com, accessed on July 30, 2011.

[20] FAOSTAT, Food and Agriculture Organization, United Nations, http://faostat.fao.org/site/291/default.aspx, accessed on July 30, 2011

[21] PriceSTAT, Food and Agriculture Organization, United Nations, http://faostat.fao.org/site/570/DesktopDefault.aspx?PageID=570\#ancor, accessed on July 30, 2011.

[22] National Agricultural Statistics Service, United States Department of Agriculture, http://www.nass.usda.gov/index.asp, accessed on July 30, 2011.

[23] Indexmundi.com, http://www.indexmundi.com/commodities, accessed on July 30, 2011.

[24] Tsao, H.-S. J., "A Framework for Evaluating Deployment Strategies for Intelligent Transportation Systems", Intelligent Transportation Systems Journal (ITS Journal), Vol.6, pp. 141-173, 2001.

[25] T. Hall and J. Luter III. Is SOA Superior? Evidence from SaaS Financial Statements. Journal Of Software, Vol. 3, No. 5, May 2008.

[26] Kondo,D., Javadi, B., Malecot, P., Cappello, F., and Anderson, D.P. (2009), "Cost-Benefit Analysis of Cloud Computing versus Desktop Grids," 2009 IEEE International Symposium on Parallel \& Distributed Processing (IPDPS).

[27] Lin, T. and Wang, S. (2009), "Cloudlet-Screen Computing: A Multicore-based, Cloud-computing-oriented, Traditional-computingcompatible Parallel Computing Paradigm for the Masses," Proceedings 2009 IEEE International Conference on Multimedia and Expo (ICME), p 1805-1808.

[28] National ICT R\&D Fund, Request for Proposals: "Establishing Center of Innovation for Use of ICT in Healthcare Sector,"; http://www.ictrdf.org.pk/, accessed on July 30, 2011.

[29] A3 BioMed Technologies, http://www.a3biomed.com/index.htm, accessed on July 30, 2011. 